\title{
Evaluar para mejorar la enseñanza en la Universidad \\ Sentido didáctico y curricular de las evaluaciones*
}

Carmen Caamaño**

\begin{abstract}
"La asimetría constitutiva del vínculo pedagógico otorga al profesor o profesora el poder de decisión sobre el 'destino' del estudiante.Este poder derivado del rol docente, circula a través del ejercicio de una serie de 'rituales' propios de la tarea pedagógica - particularmente la toma de exámenes, la administración de las calificaciones y la implementación de la sanciones institucionales - y podrá ser ejercido con justicia o despóticamente por el profesor".
\end{abstract}

Noemí Allidiére

\begin{abstract}
This work centres itself in the curricular and didactic sense of evaluation. It is an exploratory study that sought to ascertain the relation established, implicit and/or explicitly, between teaching and evaluation. For its development we opted to analyze the subsequent use that educators give to results obtained in evaluations. It conducted us to identify, to describe and to interpret the mechanisms of feedback that certain educators use in the Agrarian Area of Universidad de la República (Uruguay). The educators that participated in this investigation show that they are worried about improving the results of evaluations, since they are not seen as simple bureaucratic activities but as an integral part of teaching activities. From this study some theoretical statements could be established that show the worries of these educators in search of a responsible teaching and a more legitimate evaluation.
\end{abstract}

\section{Resumen}

Este trabajo se centró en el sentido didáctico y curricular de la evaluación. Es un estudio de tipo exploratorio que buscó averiguar la relación que se establece, implícita y/o explícitamente, entre la enseñanza y la evaluación. Para ello se optó por analizar el uso posterior que le dan los docentes a los resultados obtenidos en las evaluaciones. Ello nos condujo a identificar, describir e interpretar los mecanismos de devolución que usan ciertos docentes en el Área Agraria de la Universidad de la República. Los docentes que participaron en esta investigación muestran su preocupación por mejorar los resultados de las evaluaciones, puesto que no las ven como simples actividades burocráticas sino como parte integrante de las actividades de enseñanza. A partir de este estudio se pudieron construir algunos enunciados teóricos que muestran las preocupaciones de estos docentes por la búsqueda de una enseñanza responsable y de una evaluación más justa.

\section{1- I ntroducción}

En este artículo se exponen algunos aspectos que son el fruto de una investigación (de tipo exploratorio) realizada en el Área Agraria de la Universidad de la República (Uruguay). Fueron muchos los aspectos que nos resultaron atractivos a lo largo de este estudio, entre ellos se destaca el propio rastreo histórico del tema en cuestión: la evaluación de los aprendizajes. 
También los resultados a los que llegamos nos parecen interesantes, sobre todo, para reflexionar e intercambiar ideas acerca de los mismos. El rastreo histórico nos permitió encontrar ciertas aristas que dieron lugar a algunas conclusiones y que impulsaron la propia investigación. Un ejemplo es el caso de ciertas herencias y legados que perviven en el colectivo universitario actual y que, curiosamente, no provienen de las Universidades Medievales de los Siglos XIII al XV, sino de ámbitos confesionales jesuíticos (Siglo XVI).

A través de la Historia pueden encontrarse prácticas de exámenes formalizadas. Así en las universidades medievales (siglos XIII - XV) como por ejemplo la Universidad de París (fundada en 1215) se documentan prácticas de acreditación, surgidas como una necesidad sentida de la 'corporación de enseñantes' para incorporar nuevos miembros. Si un alumno avanzado quería ser maestro debía someterse a una ceremonia llamada, en latín, 'inceptio' ('comienzo', 'iniciación', 'ensayo inaugural'). A través de esta ceremonia se lo 'aprobaba' y se le otorgaba el derecho a enseñar, pasando a formar parte de esa corporación.

Sin embargo, pese a esa rica tradición, es el sentido de evaluación de la orden religiosa de los jesuitas la que imprimirá su característica principal a la evaluación actual en muchas de las Universidades contemporáneas. Ésta es una de las cuestiones más problemáticas y controvertidas a las que se enfrentan, en estos últimos tiempos, las Universidades. El factor más controvertido en este tema es la asociación que se hace de la evaluación con el control y el disciplinamiento; su vinculación con la ritualización vacía de significado; con el énfasis en provocar competencias individualistas; su relación con algo externo al proceso mismo del aprendizaje, o sea, el premio y el castigo; y, en definitiva, con el poder y con la regulación social.

En las Universidades Medievales, el enseñante era un tutor, incluso no mucho mayor que el postulante, que guiaba al grupo facilitando el acceso a nuevos saberes y habilidades. El maestro de los colegios jesuíticos, en cambio, actuaba como 'vigilante' (al mejor estilo foucaultiano) que funcionaba más como un preceptor que como un transmisor de saberes; entablaba con el alumno una relación asimétrica, en la que el último aparece como puerilizado, concebido como intrínsecamente débil, maleable y potencialmente corregible.

La preocupación principal de este trabajo se centró en la búsqueda y en la recuperación de ese sentido didáctico que tenía la evaluación en las antiguas Universidades Medievales y que parece bastante lejos de las evaluaciones que se hacen en nuestra Universidad. Para ello se recurrió a uno de los aspectos de la evaluación que, prácticamente, no es tenida en cuenta: las dinámicas informativas generadas por los docentes a partir de los resultados de las mismas. Primero se intentó identificar prácticas de devolución de resultados de las evaluaciones. Luego de esa identificación se buscó realizar una descripción y una interpretación de dichas prácticas y, por último se construyeron algunos enunciados teóricos que nos parecieron interesantes.

A través de esas interpretaciones se intentó desentrañar el sentido que los docentes involucrados les daban a las evaluaciones: si lo hacían con el fin de mejorar sus prácticas de enseñanza o ese aspecto quedaba relegado y se centraban en los aspectos más burocráticos de la misma.

Es innegable que la evaluación forma parte del currículum universitario, o sea, es una parte del proyecto formativo que es el currículum que cada Facultad desarrolla. Por otra parte, la formación que la Universidad ofrece posee algunas características particulares que la diferencian de la formación que se ofrece en otros ámbitos educativos. Una de estas diferencias es que la formación en las universidades tiene una doble dimensión: formativa (estrechamente vinculada a su carácter profesionalizador) y de acreditación. 
En este sentido, la Universidad garantizaría el hecho de que sus estudiantes superen los estudios que requiere la institución y completen su formación o, al menos, alcancen un nivel suficiente como para poder ejercer la profesión correspondiente.

Otro aspecto que resultó especialmente significativo al estudiar el tema fue el del manejo del poder que se evidencia a través de las evaluaciones y de cómo ese poder, aspecto de la evaluación pocas veces explicitado, llega a ser decisivo incluso en la 'regulación de la sociedad'. Ese poder suele estar solapado bajo aparentes 'buenas intenciones' (ya sea en pos del individuo, de la sociedad, de la institución...).

\section{Hacia una teoría de la evaluación}

Es importante explicitar que temíamos que la temática elegida resultase extremadamente familiar para los educadores. Este hecho tiene sus ventajas y sus desventajas. En este sentido, se debe ser consciente de que se corre el peligro de caer en varios errores, tales como los que destaca Catalina Wainerman (2000:30), en particular el que se refiere al 'Planteo de un objetivo de corte explicativo antes de haber alcanzado una descripción del fenómeno en investigación'. Para no caer en ello tuvimos especial cuidado y estuvimos muy atentos con el fin de neutralizar estos riesgos. Por consiguiente, con el propósito de que la exploración resultase más fructífera, fue muy útil comenzar dudando de los supuestos propios y someterlos a juicio crítico.

En este sentido, se intentó seguir lo que sostiene Carlino (1999: 14) en cuanto a que: “Una forma acertada de comenzar a explorar un campo temático es transformarlo en problemático, sobre todo en aquellos casos en que resulta extremadamente familiar y cercano para quien se dispone a estudiarlo, como lo es la evaluación para los educadores".

\section{Antecedentes y estado del arte de la evaluación de los aprendizajes}

Este trabajo se centró en el estudio de la evaluación concebida como 'una actividad práctica aplicada sistemáticamente a los procesos educativos'. Para muchos, este tipo de evaluación habría comenzado a cobrar importancia a principios del siglo XX pero recién podría pensarse y hablarse de un 'movimiento teórico' al respecto, a partir de los años 30. Finalmente, se institucionalizaría efectivamente a partir de la década de los 70.

Sin embargo, con respecto a la evaluación en general las investigaciones indican la existencia de prácticas sociales diversas entre las que pueden rastrearse prácticas evaluativas de larga data. Los primeros intentos de evaluar individuos se remontan al año 2000 a. de C. Así lo evidencian los estudios de D. Stufflebeam y A. Shinkfield (1993), quienes señalan que la génesis 'oficial' y documentada del tema se encontraría en China, donde funcionarios de ese gobierno dirigieron unas investigaciones de los servicios civiles con el fin de seleccionar a los mejores candidatos para ocupar cargos públicos en el gobierno. Esto los llevó a construir un sistema de exámenes cuyas características fundamentales pueden verse reflejadas aún en muchas de las prácticas de la actualidad.

También en el siglo V a. de C. los griegos (entre ellos Sócrates) utilizaron cuestionarios evaluativos como parte de su metodología didáctica. Por su parte, en Inglaterra, hacia el año 1800 , se formaron comisiones reales para evaluar los servicios públicos. El sentido didáctico se puede encontrar en el caso de los griegos. En los otros ejemplos el sentido de las evaluaciones tiene el propósito de seleccionar individuos en la sociedad, o sea, una evaluación con sentido de regulación social. 


\section{Camino hacia la institucionalización}

Se presupone que las primeras prácticas de evaluación están asociadas al surgimiento de la educación como proceso institucionalizado. Sin embargo, como ya se vio, la evaluación sería una práctica social tan antigua como las sociedades mismas.

Algunos autores como Carlino (1999:30-31) sostienen que “... a través de ella se producen, reproducen y transforman los bienes simbólicos y materiales que posibilitan la vida en sociedad. En sus orígenes más remotos y dentro de comunidades pequeñas, con poca organización, a través de la educación se transmitían saberes prácticos, escasamente sofisticados, pero imprescindibles para dominar rudimentariamente la naturaleza inmediata del ser humano..." En este caso se estaría haciendo referencia a la socialización primaria relacionada con las prácticas cotidianas y no necesariamente educativas en el sentido institucional.

Al expandirse estas pequeñas comunidades, sus modos de funcionamiento social se hacen más complejos lo que habría obligado a: crear conocimientos, saberes, habilidades; acumular esos conocimientos a través de distintos mecanismos de almacenamiento; distribuir entre los miembros de esas comunidades distintos cuerpos de saberes para garantizar la supervivencia del conjunto... Todas estas actividades estarían vinculadas con la 'división del trabajo' que se fue dando en dichas comunidades.

De este modo, las prácticas educativas comenzaron a diferenciarse y a alejarse de las prácticas domésticas cotidianas. Así habría surgido la necesidad de crear espacios sociales específicos, primero 'protoinstitucionales' y luego propiamente institucionales. Ello obligó a nombrar personas encargadas de cumplir las funciones que hasta ese momento eran desempeñadas por la familia. Ese parece haber sido el largo proceso de institucionalización de la educación y, consecuentemente, de la evaluación, diferenciándose cada vez más, estas actividades, de otras que se llevaban a cabo en la comunidad.

El historiador alemán, Robert Alt (cit. por Carlino, 1999:32), sostiene que "La adaptación de los niños que se hacía antes en forma espontánea, se hace ahora (...) de acuerdo con una escala rígida y sistemática. Se crea una escala fija de acuerdo con la cual el nuevo adulto debe demostrar si el lento proceso de adaptación ha sido suficiente. Surge así la prueba en el terreno educativo. (...) Con el desarrollo de las fuerzas productivas aparece el deseo de que los procesos educativos sean eficaces e intensivos. El éxito o el fracaso en estas tareas impulsan a medir los resultados y ponerlos a prueba. Se sabe así lo que se alcanzó en el ámbito educativo con la nueva generación y se trata de garantizar la transmisión para que sea más acabada".

\section{Evaluación, examen y enseñanza}

Díaz Barriga (1994, 1991,1990) afirma que, en sentido estricto, la historia de la evaluación, tal como se concibe actualmente, comienza en el siglo XX. Hasta ese momento sería más certero utilizar el término 'examen', de acuerdo al sentido que se le daba en las Universidades Medievales mencionadas anteriormente. Este autor considera necesario hacer una distinción entre lo que sería el 'examen' y lo que implicaría una 'evaluación' según se ha venido usando este último término en los ámbitos educativos.

Una interesante cuestión que se desprende de su abordaje es la que tiene que ver con la relación entre el examen y la enseñanza. El examen consistiría en un dispositivo utilizado al servicio de la 'buena enseñanza', así como de los procesos de aprendizaje. Como ejemplos de esta interpretación, el autor se remite tanto a las Universidades de la Edad Media como a las prescripciones que ofrece Comenio en su 'Didáctica Magna' (año 1632). 
Para Díaz Barriga, esta concepción del examen en función de la 'buena enseñanza' habría cambiado con el desarrollo de la industrialización. Para ilustrar sus afirmaciones pone como ejemplo lo sucedido en el escenario del capitalismo norteamericano a partir del siglo XIX. Es en este momento cuando habrían surgido los sistemas educativos masificados, dado que es en este momento donde aparecen urgentes y fuertes demandas sociales para la educación. Las sociedades industriales necesitaban dotar de una urgente formación básica a una gran cantidad de sujetos con el fin de obtener mano de obra barata. Al mismo tiempo, esta educación masificada requería la adopción de ciertas medidas de control para que la cuestión no se transformara en algo caótico. Se necesitaba controlar socialmente a las 'masas'a partir de un disciplinamiento adecuado (Foucault, 1992).

Este sería el momento en el que habría surgido la verdadera 'evaluación institucional', la cual adoptó, básicamente, la forma de 'pruebas objetivas' y de tests estandarizados. Estos instrumentos de evaluación constituirían los mejores recursos para que la evaluación cumpliera el tipo de objetivos propuestos ya que permiten controlar grandes poblaciones estudiantiles a través de calificaciones (asignación de notas). Es así como la evaluación pasaría a constituirse en un instrumento para ejercitar el control y el poder. Como consecuencia de este pasaje del 'examen' a la 'evaluación', se habría producido un reduccionismo que empobreció los debates en torno a la evaluación y a la propia enseñanza, entre otras cosas, porque se habría perdido la función que tenía el examen en relación a la mejora de esta última, renunciando así a su función pedagógica. Al renunciar a su función pedagógica y a toda la complejidad que la misma entraña, la evaluación pasó a cumplir una simple y reducida función de acreditación y de promoción de los estudiantes, centrándose casi exclusivamente en una dimensión técnica con una acentuada funcionalidad burocrática y política.

\section{La evaluación no es 'la cola (del currículum) que menea el perro' ${ }^{1}$}

Dado lo considerado con anterioridad, la evaluación sería una práctica pedagógica tan vieja que algunos historiadores incluso sostienen que la misma ya era parte de las primeras formas de institucionalización (y de la proto - institucionalización) de la educación. Las evaluaciones educativas son construcciones sociales adaptadas a los contextos témporo - espaciales que los sujetos deciden poner en práctica. En este sentido, tal vez no debería hablarse de un único tipo de evaluación educacional sino que sería más apropiado decir que existen distintos tipos de modelos, enfoques, perspectivas, objetos y técnicas de evaluación.

Puesto que el propósito en este trabajo estuvo guiado por la idea de que existe un sentido didáctico y curricular de las evaluaciones fue necesario analizar y reflexionar acerca de su vinculación con el 'currículum'. Este vínculo ha sido y sigue siendo bastante complejo, dado el sentido con el que se han venido manejando ambos términos: 'evaluación' y 'currículum', así como la polisemia de los mismos.

Con respecto a esta vinculación, resulta interesante acudir a planteos que hacen algunos autores. Entre otros, lo es el que propone Hargreaves (1998) en cuanto a que “...la evaluación es 'la cola (del currículum) que menea el perro'. A menudo vemos la evaluación como algo que sigue al aprendizaje, que aparece después de la enseñanza (Burgess y Adams 1985). Sin embargo, y según argumenta Broadfoot (1979), la evaluación suele tener un efecto de 'rechazo' sobre el currículum y los procesos de la enseñanza y del aprendizaje que lo acompañan. En consecuencia, la evaluación es tanto el mecanismo que hace funcionar nuestros objetivos educativos como un reflejo de los mismos (Murphy y Torrance, 1989). En este sentido, cualquier cambio en la evaluación educativa debería planificarse en consonancia con los cambios que se propongan para el currículum. 
La reforma del currículum y de la evaluación es una labor que debería emprenderse de forma conjunta, coherente y previamente planificada. De otro modo, la reforma de la evaluación se limitará a configurar el curriculum por defecto" (Hargreaves, 1998:183).

La cara oculta o menos visible de la evaluación: dimensión ética y práctica

Si la evaluación es una actividad práctica que pretende observar, analizar e interpretar la formación de los individuos involucrados en los procesos educativos, tenemos que admitir que no se trata solamente de una cuestión académica y técnica sino que consiste, sobre todo, en una cuestión ética. En realidad lo académico y lo técnico adquirirían verdadero sentido cuando están guiados por principios éticos.

Si bien, en los aspectos técnicos de la evaluación, suelen preocupar cuestiones como la 'objetividad', en los aspectos éticos deberían preocupar las acciones justas, ecuánimes y equitativas. No es que ambos aspectos sean excluyentes, sino que es importante que no se confundan.

En una evaluación, tal como se plantea en este trabajo, no se trataría tanto de ser objetivos sino de ser justos. Si estas dos categorías se confunden e identifican, tomándo las como única, se simplifican las decisiones para los docentes y los mismos pueden actuar y escudarse en función de lo administrativo, lo cual los eximiría de responsabilidades éticas. Cuando esto ocurre puede decirse que, tanto las instituciones como los docentes no tienen en cuenta las responsabilidades éticas, morales y políticas que la educación entraña.

En nuestras universidades es frecuente ver a los docentes escudarse en un accionar de reglas administrativas, muchas veces, para eludir sus propias responsabilidades éticas. Así, desde una perspectiva exclusivamente administrativa, se busca, con obsesión, encontrar las bases científicas y el sentido de la evaluación con la intención de garantizar el rigor de métodos que permitan la discriminación por vía matemática. En estos casos, las preguntas se centrarían en: qué; cuándo y cómo evaluar, o sea, las dimensiones más burocráticas y administrativas de la práctica de la evaluación.

En cambio, desde una perspectiva ética, las preguntas se deberían centrar en desentrañar cuestiones como: al servicio de quién está; qué fines persigue; qué usos se va a hacer de la información y de los resultados de la evaluación; etcétera.

Podría decirse que esta última perspectiva es la cara menos visible u oculta de la evaluación en las instituciones universitarias. Sin embargo, esta dimensión es, posiblemente, la que más efectos tenga sobre los procesos formativos.

Las consideraciones anteriores comprenden y envuelven a todos los actores involucrados en las instituciones educativas, aunque no de la misma forma. Así, cuando se habla de la evaluación de la enseñanza, se habla de evaluar al docente y cuando se habla de la evaluación del aprendizaje se habla de evaluar al alumno. Sin embargo, las consecuencias de una u otra evaluación son radicalmente distintas y de alcance muy desigual.

Al respecto, Álvarez Méndez (2000:53) afirma: "Se toman medidas respecto al alumno, y en algunos casos, medidas que afectan e inciden decididamente en la vida de los sujetos. De la evaluación de la enseñanza, se habla, simplemente. (...) La ética de la responsabilidad obliga a tener en cuenta las consecuencias que se derivan de la actuación del profesor para con los sujetos evaluados".

\section{La evaluación y el poder}

Como se expuso anteriormente, se puede decir que la evaluación conlleva una fuerte dimensión axiológica, estrechamente relacionada con el poder. Con respecto a éste, los docentes adoptan posturas más o menos democráticas. Así se pueden observar modelos donde el ejercicio del poder es unilateral, jerárquico e impositivo versus modelos más compatibles con la convivencia democrática. De esta forma pueden observarse evaluaciones autocráticas o burocráticas y evaluaciones más democráticas. 
La cuestión central y, posiblemente, más grave que entrañaría la actividad de evaluar dentro de las instituciones educativas universitarias actuales, aunque generalmente implícita, está íntimamente vinculada al ejercicio de poder. Ese poder se ejercería en forma dramáticamente asimétrica, siendo detentado por el evaluador sobre el evaluado. Es común aceptar (casi sin discusión), tanto en los ámbitos académicos como en ámbitos más populares, que el que evalúa lo hace en función del reconocimiento de su autoridad para preguntar, inspeccionar, examinar, valorar, calificar. Ello también implicaría el poder que pueden arrogarse los docentes de vilipendiar a los estudiantes a través de la exposición pública de sus resultados. Por lo tanto, en el caso de la evaluación educativa, parece reconocérsele al docente una investidura de autoridad en cuanto a su rol para jerarquizar y seleccionar personas, lo que excedería ampliamente la simple evaluación de conocimientos. Si esto se analiza con espíritu crítico se verá la gravedad de la cuestión.

Cuando se evalúa se trata de sopesar y de valorar pruebas, de calificar a un sujeto y de tomar decisiones respecto de su situación. Evaluar, tal como se ha generalizado y aplicado el término hoy día, implica establecer un juicio de valor acerca de una cosa o persona. Parece razonable pensar, entonces, que el evaluador no sería un simple analizador de datos sino alguien que juzga y que toma decisiones, lo que se vincula estrechamente con el poder de premiar, castigar, vigilar. Estas posturas suelen verse con bastante frecuentes en nuestra Universidad y parecen corresponderse más con la búsqueda de una 'enseñanza exitosa' que con la de una 'buena enseñanza'. Son diversos los autores que abordan este tema del poder en la evaluación, sobre todo en las organizaciones institucionales de educación. Gvirtz y Palamidessi (1998: 251), al referirse al ejercicio del poder llevado a cabo en el día a día en las aulas, sostienen que "La evaluación siempre está ligada al ejercicio del poder y de la autoridad: hay alguien que sabe y alguien que no sabe; el primero tiene la legitimidad institucional para determinar cuánto se sabe o si se es correcta o moral la conducta del segundo y, a la vez, tiene el poder de calificar ('Sánchez sos un bocho' o 'Ese pibe del fondo, Vitali, es de madera'), sancionar o promover a las personas".

Esta investidura del poder suele acarrear consecuencias nefastas para el individuo que es evaluado, sobre todo cuando el poder es manejado sin la debida responsabilidad ética y moral. En casos como el ejemplo mencionado anteriormente, en lugar de favorecer el aprendizaje de los alumnos y, al mismo tiempo, mejorar la enseñanza del docente, seguramente tendrá un efecto contrario, constituyéndose en un fuerte obstáculo para una formación adecuada, pudiendo tener alta incidencia en la autoestima (positiva o negativa) del que aprende.

Popkewitz (1994) también relaciona la educación y, especialmente, la formación del profesorado con la cuestión del poder y de la regulación de la sociedad. Ello queda claramente de manifiesto en un trabajo en el que hace un estudio comparado de ocho casos de reformas educativas llevadas a cabo en los últimos tiempos en distintos países. Sostiene que “... los cambios en la regulación y el poder de la sociedad son evidentes en la intersección de universidades, comunidades de investigación, escuelas y el Estado en la medida en que la reforma de la formación del profesorado produce nuevas regulaciones sociales" (1994:40).

El autor vincula la educación, en especial la universitaria, con la gestión estatal. Al respecto dice: "Desde la creación de las universidades orientadas a la investigación en Prusia y el advenimiento de la educación profesional en la Francia napoleónica, la educación superior ha sido un elemento importante de la gestión estatal, a pesar de lo cual se han explorado muy poco sus relaciones y dinámicas específicas. El enfoque puesto sobre la formación del profesorado pone nítidamente de relieve las relaciones entre planificación académica y estatal, las suposiciones y valores del conocimiento disciplinario en la enseñanza, y los valores centrales sobre Pedagogía que se configuran en el trabajo de la enseñanza" (1994:48). 
En el tratamiento de este tema el autor parece encontrarse fuertemente influenciado por el pensamiento foucaultiano (a quien cita). Esto se torna más evidente cuando relaciona la cuestión del poder con las 'prácticas discursivas' que se utilizan en la enseñanza. Las mismas constituirían una manera de 'leer' las pautas de interacción y de negociación que se dan en los distintos ámbitos sociales, especialmente en los educativos.

Foucault, en un esfuerzo por comprender cómo se ejerce el poder y el control en la vida moderna, centró sus estudios en la arquitectura y en las configuraciones espaciales de las organizaciones institucionales (educativas, castrenses, de salud, etc.). Sostiene que el conocimiento de nuestro mundo social toma una 'forma' y es ella la que determina cómo construimos las relaciones individuales y establecemos las prioridades y las pautas que deberán usar los individuos para interiorizar la organización social y, consecuentemente, disciplinarse a sí mismos.

Las 'prácticas discursivas' constituirían un elemento primordial en toda esta arquitectura social. Para Foucault (1992), parafraseado por Popkewitz (1994:49-50), las 'prácticas discursivas' remitirían "al conjunto de reglas anónimas, históricas, siempre determinadas en el tiempo y en el espacio que definen una época y, más concretamente, dentro de un área social, económica, geográfica y lingüística dada, las condiciones de ejercicio del habla, de la función enunciativa. De este modo, las reglas del discurso rigen lo que se puede decir y lo que no se puede decir, identificando quién puede hablar con autoridad y quién debe escuchar. Son anónimas porque no hay ningún autor identificable, y tampoco tienen un comienzo claramente definido".

Las 'prácticas discursivas' no deben verse solamente como formas de generar discursos sino como incorporaciones a los procesos técnicos, a las instituciones y a las pautas de comportamiento en general. Las mismas se dan a través de formas de transmisión y de difusión, así como en formas pedagógicas que las imponen y las mantienen simultáneamente. En este sentido, puede decirse que las 'prácticas discursivas' tienen que ver con las reglas de comunicación que estructuran ciertas posibilidades, así como filtran y descartan otras.

En otras obras, siguiendo también a M. Foucault (1992), Popkewitz (1991:9) aborda el mismo tema desde los códigos y las relaciones de poder. Sostiene que "El lenguaje de la educación del profesorado, sus rituales y la forma en que en ella se actúa, existen dentro de un contexto institucional. La conducta se estructura según unos códigos de cultura que determinan la forma en que las personas piensan, sienten, 'ven' y actúan frente a la práctica de la escuela".

A medida que las instituciones educativas evolucionaron como sistemas sociales con el fin de preparar al sujeto para la vida, se fue desarrollando también un grupo ocupacional (los profesores y maestros) que fue ejerciendo el control y la autoridad en el quehacer diario de esas instituciones. Este grupo ocupacional fue creando un cuerpo especializado de imágenes, de alegorías y de rituales que legitimaban su existencia y ordenaban los trabajos que comportaba. O sea, las instituciones educativas y las personas que les fueron dando forma fabricaron un mecanismo de legitimación de sus modelos ocupacionales y de trabajo, que los investía de poder frente a los neófitos.

Podría decirse que esta situación se extendió también hacia el interior del mundo académico, a medida que se producían cada vez más especializaciones e hiper-especializaciones en los distintos campos del conocimiento. En este sentido es que podría hablarse de la formación de 'tribus académicas', tal como lo plantean autores como Becher (2001), Bailey (1977) y otros. Becher cita a Bailey, en el acápite que da inicio a su libro, de la siguiente forma: "Cada tribu posee un nombre y un territorio, arregla sus propios asuntos, va a la guerra, tiene una lengua o, al menos, un dialecto distintivo y diversas maneras de demostrar que es diferente a las otras". 
Esta situación también tiende a ver como neófitos a los miembros de otras áreas temáticas, de otras 'tribus académicas'.

Siguiendo este razonamiento, parece comprenderse mejor el poder y el vigor que entrañan estos modelos sociales en la enseñanza y en la evaluación. Ello será posible si se puede llegar a desentrañar la diferencia que hay entre el sentido superficial y el sentido profundo de la vida institucional. El primero estaría dado por los criterios o niveles aceptados públicamente con los que las personas juzgan y miden el éxito o el fracaso. El sentido profundo estaría representado por los supuestos y las 'reglas de juego' que dan plausibilidad y legitimidad a las actuaciones concretas. La evaluación estaría, entonces, estrechamente vinculada a esta cuestión del poder y de la legitimación institucional.

\section{Evaluación, enseñanza, 'prácticas de enseñanza'}

En el caso del término 'enseñanza' podemos encontrar múltiples definiciones. Muchas de ellas responden a posicionamientos paradigmáticos (y posturas ideológicas) declarados o implícitos que se manejan en cada época y lugar. La concepción de lo que significa 'enseñanza' también puede darse desde la aproximación personal que hagan los docentes con respecto al acto de enseñar. Ello dependerá, en buena medida, de sus propias historias académicas, sus historias de vida, sus características personales y otros factores. Por lo tanto, es razonable pensar que existen distintas prácticas de enseñanza. Pero, ¿cuáles serían las mejores prácticas de enseñanza? ¿Existen unas mejores que otras?

Jackson (2002:132), desde la perspectiva de un enfoque evolutivo, sostiene que las prácticas de enseñanza responden a un determinado tiempo y a unas determinadas circunstancias. Por ello resultaría muy arriesgado afirmar que unas prácticas de enseñanza son mejores que otras. Al respecto, pregunta: “¿Quiénes son los verdaderos docentes y cuál es la verdadera enseñanza? No hay tal cosa, dice la persona que ha adoptado un punto de vista evolutivo. Hay interpretaciones de hechos, incluyendo aquellos cuyos protagonistas son docentes. Hay argumentos que pueden esgrimirse a favor de ésta o aquella práctica de enseñanza. Algunos argumentos son mejores que otros. Sin duda hay algunas prácticas que la mayoría de los que enseñamos hoy, estamos dispuestos a defender. Parte de nuestra responsabilidad profesional es ejercer esa defensa". Según este enfoque no habría una definición única de 'enseñanza' válida para todo tiempo y lugar. Existiría, sí, una actividad que se llama 'enseñanza' y esa actividad sería la que nos permite intentar distinguir entre 'buena' y 'mala enseñanza'. Pero, no se podría hablar de 'enseñanza' en un sentido universal del término sino que la misma estaría enmarcada en el contexto cultural (témporo - espacial) en el que esta actividad se desenvuelve.

Reconociendo la compleja realidad con respecto a la 'enseñanza', nos resultó interesante incorporar la perspectiva de Fenstermacher, ubicándola dentro de lo que Liston y Zeichner (1997: 91) llama "un modelo de investigación reflexiva: el modelo de argumentación práctico". Fenstermacher ve la 'enseñanza' como “... aquella relación que se establece por lo menos entre dos personas, una de las cuales posee un cierto conocimiento, habilidad u otra forma de contenido que pretende transmitir a otra que carece de él" (1989:150).

Desde algunos modelos educativos, se suele insistir en que la relación que hay entre la enseñanza y el aprendizaje es de tipo causal. Sin duda, hay una relación entre 'enseñanza' y 'aprendizaje'. Sin embargo, siguiendo al autor citado, esa relación no sería de naturaleza causal sino ontológica, lo que implica que cuando se enseña se espera que otro aprenda, pero que esto último no está garantizado. En este sentido, la 'enseñanza' sería un 'intento' de que otro aprendiera. Debería ser una actividad que busque favorecer el aprendizaje, de lo contrario no tendría razón de ser. 
En esta concepción subyace la idea de que en la educación se darían dos procesos perfectamente diferenciados pero que, en algún momento se entrecruzan (en una especie de 'zona de intersección'): el proceso o actividad de enseñanza y el proceso de aprendizaje. En esta zona de intersección se pueden dar distintos resultados. No todo lo que se pretende enseñar es aprendido, o no es aprendido tal como espera el docente que lo sea, o se aprende algo que no estaba previsto, no todos aprenden lo mismo... Ello sería consecuencia de múltiples causas: unas provenientes del propio educador, otras que provienen del educando, otras que provienen de la propia disciplina, otras del contexto cultural, etcétera.

Lo que es indudable es que en esta labor tiene que construirse una zona de contacto interpersonal entre educador y educando. Esta tarea es, básicamente, responsabilidad del docente, al menos como instaurador, sostenedor y potenciador de la misma. Tal vez ésta sea una de las tareas centrales del enseñante: habilitar ese espacio de intersección y, al mismo tiempo, ampliarlo cada vez más, con el fin de posibilitar una mejor intervención, buscando lograr una mejor enseñanza que, sin duda, incluye la evaluación.

Desde esta perspectiva, la enseñanza debería generar un andamiaje con el fin de facilitar el aprendizaje de algo que el estudiante puede hacer si se le brinda la ayuda necesaria. En esta última consideración estaría subyaciendo la idea de que hay aprendizajes que el sujeto puede hacer 'sin ayuda' y otros que requieren esa ayuda, ya sea por su complejidad, por lo desconocido del tema o por otras razones. En este sentido es que sería razonable pensar en la enseñanza como una relación asimétrica.

¿Por qué resulta pertinente recalcar la relación que se da entre los procesos de enseñanza y de aprendizaje? Una de las razones más importantes es que, de acuerdo a cómo se considere esta relación también va a ser diferente el modo de intervención docente, lo que incluye la evaluación considerada como parte de la enseñanza.

Si se considera que la relación que se da entre enseñanza y aprendizaje es de naturaleza ontológica, las intervenciones didácticas que incluyeran la evaluación, tendrían en cuenta una máxima fundamental: la conciencia de que la enseñanza es solamente un intento. Ello implica que se debe hacer un enorme esfuerzo para que sea el mejor intento. Por otra parte, se tendrá presente que el resultado de ese intento no será el mismo para todos los que aprenden ni se logrará en los mismos tiempos.

Por el contrario, en una postura en la que se considere que hay una dependencia de tipo causal significaría, entre otras cosas, sostener la idea de que existe un solo proceso, generalmente conocido a través del binomio: 'proceso de enseñanza - aprendizaje'. Una relación de tipo causal implicaría que se tiende a identificar el aprendizaje con el rendimiento, por lo que la 'buena enseñanza' sería confundida con el éxito que tenga o no el alumno (con una 'enseñanza exitosa'), en forma más o menos inmediata para todos. Una forma de evidenciar este aprendizaje exitoso sería el momento de una prueba de evaluación puntual igual para todos.

Por su parte, Álvarez Méndez habla de un ‘éxito compartido' cuando se refiere a ‘enseñar bien, aprender bien' (2000:45). La relación que se establece entre 'enseñanza' y 'evaluación' tendría que ver con estas expresiones. Se refiere a que, a pesar de que la enseñanza y el aprendizaje son procesos diferentes, se espera que tanto el docente como el alumno asuman sus responsabilidades en el proceso educativo. En este sentido, podría aceptarse que el éxito de uno se puede valorar por el éxito del otro. 
Al hablar del enseñante y de lo que considera 'buena enseñanza' en relación con la evaluación dice: "Difícilmente se pueda aceptar sin más argumentos que 'es un buen profesor, aunque suspende a muchos'. Moralmente es inadmisible aceptar que el profesor sea valorado positivamente por el fracaso que produce (...) Pero un 'buen' profesor es sobre todo el que garantiza el éxito a todos aquellos que están dispuestos a alcanzarlo, sin trampas, sin cortapisas, sin dobles lenguajes, como decimos del 'buen alfarero' porque consigue con su quehacer artesanal obras de valor estético. (...) En este sentido, es buen profesor sobre todo porque trabaja con intención formativa y no ahorra esfuerzos para conseguir que quienes aprenden con él lo hagan de un modo que garantice el éxito en ese esfuerzo compartido" (Álvarez Méndez, 2000:4 y 46).

Postula que cuando lo que preocupa, tanto al docente como a la institución, es ser justo y equitativo, el propio sujeto de evaluación deberá participar activamente en la misma dentro de un marco de tranquilidad (de un 'ambiente de bajo riesgo') tal que le asegure que el profesor nunca actuará en su contra 'por caminos retorcidos' (Álvarez Méndez, 2000:81).

Fenstermacher (1989) afirma que “...la palabra 'buena' tiene tanto fuerza moral como epistemológica. Preguntar qué es buena enseñanza en el sentido moral equivale a preguntar qué acciones docentes pueden justificarse basándose en principios morales. Preguntar qué es buena enseñanza en el sentido epistemológico es preguntar si lo que se enseña es racionalmente justificable y, en última instancia, digno de que el estudiante lo conozca, lo crea o lo entienda" (1989:158).

Litwin (1997:95), por su parte, sostiene que la dimensión moral de la enseñanza “...se expresa en la forma de abordar el contenido, en los ejemplos con los que se da contenido al contenido, en la actitud del docente que, cuando termina la clase, en su casa o en su mesa de trabajo, realiza un cuadro para recuperar en la siguiente los temas, que guarda los exámenes de los alumnos, que acepta sus intervenciones y da respuesta inmediata a sus preguntas".

Es importante destacar y tener en cuenta lo que sostiene Litwin con respecto a las 'prácticas de enseñanza', entre otras cosas, por el aspecto ideológico que se destaca en la cita y que debería hacernos reflexionar acerca de nuestras propias prácticas: “Las prácticas de la enseñanza presuponen una identificación ideológica que hace que los docentes estructuren ese campo de una manera particular y realicen un recorte disciplinario personal, fruto de sus historias, perspectivas y también limitaciones (...) Ilevan a cabo las prácticas en contextos que las significan y en donde se visualizan planificaciones, rutinas y actividades que dan cuenta de este entramado" (1997:95).

\section{Abordaje metodológico}

\section{Creación y re-creación del diseño de investigación}

La metodología se planteó desde una perspectiva cualitativa. Ello implica que este estudio se inscribe en una metodología caracterizada por la producción de datos descriptivos, obtenidos a través de las percepciones, las acciones y los dichos de los sujetos involucrados.

Puede decirse que se trató de una investigación de tipo inductivo puesto que, a partir de los datos obtenidos, se llegó a la interpretación de los mismos y a la elaboración de posibles conceptos, mini-teorías o enunciados teóricos que pudieran dar cuenta de esas interpretaciones. O sea, los datos no se recogieron con el fin de comprobar hipótesis, sino de construir algunos enunciados teóricos o posibles categorías de análisis. Todo el trabajo tuvo un carácter flexible puesto que siguió lineamientos orientadores pero no reglas predeterminadas. ${ }^{3}$ 
Dada su condición naturalista este tipo de investigación suele llevar a que el accionar del investigador cause efectos sobre las personas que son objeto de estudio. Es por eso que se intentó interactuar con los investigados de la manera más natural posible, tratando de reducir al máximo ese efecto pero teniéndolo en cuenta a la hora de interpretar los datos.

El diseño, plan, dispositivo o estrategia de investigación que se utilizó permitió, finalmente, establecer algunos enunciados teóricos o categorías interpretativas que pueden dar cuenta del sentido didáctico y curricular de las evaluaciones. Esto se realizó, básicamente, a través del estudio de los mecanismos de devolución de los resultados de las evaluaciones que utilizan los docentes para comunicárselos a sus estudiantes.

Buscando construir estos enunciados es que se procuró establecer y llevar adelante un diseño de tipo emergente, dinámico y flexible en el que se plantearan los instrumentos seleccionados pero que al mismo tiempo permitiera al investigador abrirse a la formulación de probables cambios si la situación investigativa así lo ameritaba.

\section{La flexibilidad obliga.}

Al avanzar la investigación, el diseño original resultó un tanto estrecho ya que no permitía trabajar con la necesaria flexibilidad y en forma lo más natural posible. Por lo tanto, en una segunda instancia, algunas cosas cambiaron: entre ellas, el valor que se le había asignado a la triangulación de datos con el fin de validad rigurosamente los mismos. Ante esta necesidad se cambiaron los referentes teóricos y se adoptó la propuesta que hace P. Woods (1998).

Lo que propone este autor para los estudios etnográficos refleja con mayor exactitud lo que se pretendía de esta investigación: "Los etnógrafos científicos aducirán los méritos del naturalismo (sutil), la validación respondiente y la triangulación como instrumentos para establecer la validez (...) Sin embargo, para algunos investigadores posmodernos, este punto de vista es demasiado limitado, dado que el triángulo está fijo y es bidimensional. Richardson (1994, pág. 522), por ejemplo, prefiere hablar de 'cristalización' ya que el cristal 'combina la simetría y la sustancia con una infinita variedad de formas, sustancias, transmutaciones, múltiples dimensiones y ángulos de enfoque. Los cristales crecen, se alteran, pero no son amorfos' (Woods, 1998: 80)".

Esta perspectiva identificaba mucho más claramente lo que buscábamos con este trabajo. No se trataba de una triangulación que validara ciertos datos sino de algo que fuera mucho más allá. Adoptar la postura de Woods implicaba, sin duda, apuntar a un proyecto mucho más ambicioso, entre otras cosas, porque desafía con fuerza la imaginación del investigador y sus posibilidades creativas. Por otra parte, enfatiza el involucramiento de sus propios sentimientos cuando investiga con pasión y con compromiso ("el yo etnográfico").

Una de las preocupaciones de esta investigación era saber si el sujeto estaba diciendo la verdad tal como él la entendía (esa es su verdad) más que comprobar obsesivamente 'una cierta verdad' más allá de la que el sujeto manifiesta. En este caso se trata de hacer un análisis considerando que el investigado hace referencia a sucesos e incidentes, sobre todo en los casos en los que "el sujeto es la clave del asunto, porque entonces lo que se considera real lo es según sus consecuencias (Thomas, 1928 - cit. por Woods, 1998:80)..."

En otras circunstancias, con propósitos diferentes, los hechos reales podrían resultar cruciales, lo cual puede ameritar un ineludible trabajo de verificación, pasible de hacerse a través de una triangulación. "Para el investigador o la investigadora, esto supone un cierto trabajo de verificación, que es donde entran en juego las prácticas habituales de triangulación, inmersión, validación respondiente y cosas por el estilo" (Woods, 1998: 80). 
Pero, ¿qué resultaba más apropiado e interesante para los propósitos de este trabajo: hacer una 'verificación' o realizar una 'exploración'? En cuanto a la orientación metodológica que se intentó imprimir a esta investigación podría decirse que correspondía realizar una labor de exploración con el fin de entender tanto la 'conciencia práctica' con la que opera el agente (investigado) como alguno de sus fundamentos y motivaciones más ocultas. ¿Qué tipo de exploración se tenía que hacer para lograr este fin?

Lo más atrayente de esta investigación fue la labor de 'exploración' que implicaba y no tanto la de verificación porque, como dice Woods: "La exploración es más bien una labor artística, y la verificación es algo científico; (y que) ésta es una conjunción frecuente dentro de la investigación cualitativa (...) no me gustaría que la investigación se viera limitada y dominada por una aplicación rigurosa de la plausibilidad y los criterios de credibilidad, ni caer en la exigencia de probar los resultados de un modo formal y específico, con estrecheces. Esto me parece que impide acceder al material interesante, que no es susceptible a esa forma de test" (Woods, 1998: 81). A partir de los insumos ofrecidos por este autor fue que se tomó la decisión de realizar la exploración siguiendo ese camino.

La lectura de Woods nos permitió encontrar cierta solución a una de nuestras inquietudes y preocupaciones que estaba planteada desde el inicio de la investigación: la excesiva búsqueda de una rigurosa validez de los resultados que debería encontrar. Esta postura metodológica, de corte etnográfico, conformaba mejor el sentido perseguido y nos permitió sentirnos con más libertad para la acción. Un enfoque de este tipo otorga más margen de flexibilidad y no encorseta "con estrecheces", tal como lo sostiene el mismo autor: "La etnografía, con sus énfasis sobre el respeto hacia el mundo empírico, los penetrantes niveles el significado, el facilitar 'adoptar el papel de otra persona' definiendo situaciones y obteniendo una sensación de progreso, es la metodología natural de semejante enfoque, y para intentar comprender el 'arte de la enseñanza'. Idealmente hablando, la práctica de la propia etnografía es tanto ciencia como arte. Es un enfoque abierto, no predeterminado, inductivo con más frecuencia que deductivo, con teorías generadas por y basadas en los datos. Los etnógrafos no saben qué descubrirán. La labor inicial suele ser típicamente complicada y caótica, hasta que empiezan a surgir los temas centrales. La etnografía es un acto de fe, que requiere una fuerte voluntad inicial" (Woods, 1998:22).

\section{Técnicas o instrumentos utilizados para la recolección de datos}

Para la recolección de datos, las principales técnicas utilizadas fueron las siguientes:

- Análisis de contenidos - documentos que pudieran haber elaborado los docentes (informes, reflexiones, relatorios, anotaciones, etc.) con relación a las evaluaciones y las devoluciones de resultados de las mismas.

- Entrevistas informales, generales (a todos los docentes) y entrevistas en profundidad muy focalizadas (solamente a algunos docentes). Estas últimas fueron elaboradas para cada uno de los docentes en forma individual puesto que estaban planificadas para profundizar aspectos a los que habían aludido en sus documentos y en los cuestionarios realizados.

- Breves cuestionarios escritos con el fin de profundizar ciertos aspectos que fueron surgiendo a partir de los documentos y de algunas entrevistas informales. 


\section{Características de las instituciones y de los docentes}

La investigación se llevó a cabo en dos Facultades que conforman el Área Agraria pertenecientes a la Universidad de la República: Facultad de Agronomía y Facultad de Veterinaria. Los docentes investigados (doce en total) pertenecen a los siguientes cursos: CIEV (Curso Introductorio a los Estudios Veterinarios), Epidemiología; Histología; Clínica Quirúrgica; Pequeños Animales; Química; Instituto de Pesca; Toxicología; Áreas Forestales; Cardiología. En el estudio participaron desde Colaboradores Honorarios hasta grados 5.

El Área Agraria está integrada por dos Instituciones con fuertes tradiciones en el medio universitario (más de cien años de existencia). La gran mayoría de sus docentes no tiene formación pedagógica, pues de acuerdo a la tradición institucional su labor se centra en la investigación. Ello, tal como sostiene Sarason (2002) puede constituirse en un peligroso error: "Yo no había hecho ningún curso formal ni informal de capacitación docente. En el nivel universitario se parte del supuesto de que si uno conoce su materia, la enseñará bien a los alumnos. Sabía que eso era un desatino autorreferencial". ${ }^{4}$

Cualquiera de las dos Instituciones se caracteriza por contar con grupos masificados, sobre todo en los primeros años de las carreras, con las dificultades que esto acarrea para llevar a cabo una buena enseñanza (tal como lo manifiestan los docentes investigados).

El diseño pensado y llevado adelante contó con tres informantes a los que se acudió con el fin de que orientaran al investigador hacia la localización de docentes que eran considerados como 'buenos enseñantes', que se preocupaban por la enseñanza y por la evaluación En este sentido, se hizo una selección intencionada de sujetos en función de algunos criterios que se habían establecido con anterioridad.

El interés fue el de trabajar con profesores comprometidos con su tarea, considerados como docentes que tenían 'buenas prácticas de enseñanza'. Al mismo tiempo deberían cumplir con ciertos requisitos que, de alguna forma, facilitaran la 'entrada' a esta temática: tener cierta experiencia como docentes en la Universidad; haber realizado algún curso de los que brinda el Departamento de Educación Veterinaria (ex - Unidad de Apoyo Pedagógico), en especial los cursos de 'Evaluación'. Al mismo tiempo se buscó que en el grupo de investigados estuvieran representados todos los Grados (desde el Grado 1 hasta el Grado 5).

En la selección de los docentes se intentó cubrir el mayor espectro posible en relación a la pertenencia a las distintas Cátedras, a los distintos Cursos, Departamentos o Institutos. Se hizo una primera selección de unos veinte (20) docentes que cumplían con los requisitos propuestos. Luego, la cantidad se redujo a doce (12) por diversos motivos (debidos a viajes al exterior en forma prolongada de algunos; cierta resistencia a continuar con el proyecto, por parte de otros...).

Si bien la muestra no es grande, puede decirse que se logró apreciar una especie de 'tendencia' de estos docentes hacia la consideración de las cuestiones didácticas que involucra la evaluación. Dado que el propósito de esta investigación no es que los resultados sean generalizables, esta tendencia nos sirvió para construir algunos enunciados teóricos que pueden resultar provechosos para la profundización de los aspectos didácticos abordados a nivel universitario.

\section{La ardua tarea de construir enunciados teóricos o mini- teorías interpretativas}

Lo que pudimos construir a partir de esta investigación puede ser entendido como una serie de 'enunciados teóricos'. Para ello fue necesario elaborar y recorrer 'un mapa' diferente al conocido 
desde las teorías de otros. Aquí nos vimos en la necesidad de construir una teoría interpretativa propia. Ello se hizo a partir de huellas que se iban encontrando en el recorrido, aun con la conciencia de que ese mapa que se estaba construyendo sólo podrá dar cuenta de la provisionalidad de alguna mini-teoría.

Esta labor de intentar construir nuevas teorías fue el aspecto que resultó más creativo, interesante y desafiante en el trabajo de investigación. Exige al investigador la construcción y creación de ese mapa que debería convertirse en un nuevo aporte teórico a la temática abordada. Con ese propósito, se comenzó a hacer un estudio pormenorizado de los datos obtenidos, lo que nos obligó a 'leerlos' desde varios niveles de análisis. A partir de las primeras lecturas se fueron construyendo grandes dimensiones que se desprendían de los materiales aportados por cada docente. Muchas de esas grandes dimensiones se evidenciaban, de una o de otra forma, en la mayoría de sus expresiones.

Las manifestaciones de los docentes se pudieron ir agrupando de acuerdo a las recurrencias que presentaban, lo cual nos llevó a la necesidad de otorgar nombres que dieran cuenta de esos grupos. Este trabajo se fue haciendo de distintas formas: primero en forma literal, luego buscando recurrencias, más tarde cruzando datos y agrupándolos y, finalmente, elaborando cuadros de doble entrada o matrices de análisis, hasta volver a reflexionar sobre toda esa construcción, hacerle modificaciones, etc.

Con el fin de seguir organizando el trabajo, se empezó a comparar los componentes que se encontraban dentro de cada gran dimensión y a buscar dominios más inclusores que finalmente nos condujeron a la construcción de algunos enunciados teóricos básicos que pudieran dar cuenta de ciertas interpretaciones acerca del problema que se había planteado en el trabajo.

\section{Algunos enunciados teóricos}

I.- Un compromiso didáctico de los docentes: la búsqueda de mecanismos alternativos de devolución de resultados

Este enunciado, de acuerdo con los datos obtenidos, se puede desglosar en algunos subenunciados. La búsqueda de nuevas formas de devolución por parte de los docentes investigados surge de sus preocupaciones con respecto de la forma en que encaran la actividad de evaluación y también la actividad de enseñanza. En ese sentido podría decirse que la mayoría de estos docentes busca mecanismos alternativos de devolución de resultados, lo que podría interpretarse como una especie de compromiso y desafío didáctico (y hasta moral). Algunos de los mecanismos de devolución se detallan a continuación.

\section{a.- Más allá de las devoluciones a través de los espacios públicos (cartelera...)}

Se trata de formas esporádicas, puntuales y no sistematizadas de devolución que utilizan algunos docentes. La devolución de los resultados de las evaluaciones a través de las carteleras y de las páginas Web es la forma más tradicional que existe en la Universidad de la República. A pesar de que este mecanismo de devolución está tan profundamente instalado en la tradición universitaria, muchos profesores buscan formas alternativas que resulten más enriquecedoras para el aprendizaje de sus estudiantes. La dificultad está, según los propios docentes, en que las formas alternativas implican mucho más esfuerzo y tiempo del que no suelen disponer. De ahí que ante la realidad de grupos muchas veces masificados terminan por abandonar algunos emprendimientos muy buenos. 


\section{b.- Otras formas de devolución que tiende a sistematizarse}

Otros docentes interactúan en forma diferente con los resultados y con los estudiantes. La mayoría de ellos, sin dejar de comunicar los resultados por las vías tradicionales, realizan otras actividades que involucran a sus estudiantes. Los invitan a conversar con ellos acerca de cada resultado en forma individual. Estas prácticas no se realizan en forma sistemática, ni con carácter institucional. Tal vez, si así se hiciera, podrían resultar muy valiosas para el proceso educativo porque los estudiantes seguirían aprendiendo en forma personalizada a partir de sus propias evaluaciones, de sus aciertos y de sus errores. Por otra parte, el docente tendría la oportunidad de seguir enseñando y, seguramente, profundizando en aspectos que tal vez pensó que habían quedado suficientemente claros para todos sus estudiantes durante el curso. En estas entrevistas personalizadas, incluso hubo docentes que declararon haber modificado algún resultado luego de esas entrevistas individualizadas cuando se evidenciaba un error en la corrección.

Esta parece ser una buena práctica de devolución. El mayor problema que se observa es el de que los docentes no siempre tienen el tiempo suficiente para atender a todos los que concurren con la atención que merecen, debido -según ellos-, al problema de la masificación.

\section{c.- Las gráficas como dispositivos didácticos en las devoluciones colectivas}

Algunos docentes plantean una devolución de las evaluaciones parciales a través de un mecanismo interesante: lo hacen a través de gráficas estadísticas en las que aparecen los resultados obtenidos (en general, bajos). Se analizan en forma grupal, excediendo la propia evaluación puntual. Los docentes pretenden "asustarlos un poco para que estudien más para el siguiente parcial”. Esta forma de calcular, graficar y comunicar los resultados da bastante trabajo por lo que no siempre se hace.

En esta actitud de los docentes se evidencia una clara intención de ayudar a que los estudiantes aprendan más y mejor. En ningún momento surgió la idea de excluirlos ni de que el único fin fuera el de acreditarlos. Nos atrevemos a afirmar que estas devoluciones conllevan un fuerte componente de responsabilidad y del sentido didáctico que tiene para ellos la evaluación.

\section{d.- El tipo de examen determina el mecanismo de devolución}

Los docentes manifiestan la necesidad de utilizar mecanismos diferentes de devolución de acuerdo al tipo de examen. Los cursos teóricos y teórico-prácticos, deben proponer exámenes diferentes, por lo tanto, también las devoluciones exigen formas distintas. Cada una de esas instancias de evaluación requiere, no solamente instrumentos diferentes sino también formas de interactuar con los resultados de los alumnos en forma distinta. Ejemplos claros surgen de los prácticos en cirugía, cuyos procedimientos requieren un seguimiento y monitoreo constante y de tipo individual, en el momento mismo de su realización.

\section{e.- De ensayos y representaciones}

En este caso nos encontramos con mecanismos de intervención previos a la evaluación. Esta preocupación de los docentes parece estar indicando claramente la intención de ayudar a sus estudiantes a mejorar sus resultados, evitando que se encuentren con obstáculos innecesarios. Los docentes realizan una ejercitación del instrumento de evaluación que usarán con sus alumnos en los parciales y en los exámenes finales. Parecen ser ensayos programados que suelen realizarse sistemáticamente. Opinan que esta forma de ejercitarse tiene que ver con poner al estudiante en contacto con algo que no conocen y así evitar que en el momento de la evaluación los tome por sorpresa y se convierta en un obstáculo que no es precisamente de orden pedagógico. O sea, lo que hacen es una especie de ensayos y representaciones con el fin de preparar a los 
estudiantes para el día de la 'evaluación real' para mejorar los resultados de los estudiantes en situaciones de 'alto riesgo'. Son totalmente conscientes de lo que los estudiantes arriesgan en las evaluaciones.

\section{f.- La danza de una tríada dialéctica}

La mayoría de los docentes que colaboraron en este trabajo coinciden en que existe una relación triádica entre la enseñanza, el aprendizaje y la evaluación. En esa tríada tal vez el punto más débil esté en el tratamiento que se le da a la evaluación y, consecuentemente, a las formas de devolución de los resultados de la misma. Una de las docentes encargada de un curso sostiene que "La prueba inicial (...) cumple su función diagnóstica ya que a partir de ella los docentes obtienen la información relativa al nivel de conocimientos previos que se consideran esenciales como punto de partida para facilitar nuevos aprendizajes". Este tipo de evaluación les sirve a los docentes para la planificación del curso y en función de ella, saber desde qué nivel real de desarrollo parten sus estudiantes. Las pruebas formativas tienen otros propósitos para este grupo de docentes, en especial, dos son los cometidos: el primero tiene que ver con la devolución de los resultados a los estudiantes y el segundo persigue la retroalimentación de los procesos de enseñanza.

La mayoría considera que las evaluaciones diagnósticas y las devoluciones podrían tener un interesante valor pedagógico pero también exponen las dificultades con las que se encuentran para llevarlas a la práctica en forma adecuada. Una de ellas es el hecho de que las mismas tienen que desarrollarse fuera de los horarios reglamentarios.

\section{g.- Devolución en acción}

Este tipo de mecanismos de devolución se vinculan estrechamente con la propuesta de una evaluación formativa en 'acción'. Hay docentes que están plenamente convencidos de que no pueden separar la evaluación de lo que implica todo su curso, desde los objetivos, los contenidos, las actividades, las actitudes, etc. En el curso de Cardiología, por ejemplo, los estudiantes tienen que trabajar con pacientes reales que llegan a consulta. La mayoría de las decisiones son discutidas entre todos los integrantes (estudiantes y docente). La evaluación también se planifica y se hace en conjunto ajustándosla sobre la marcha, de acuerdo con los casos concretos que se presentan y las competencias que demuestran los estudiantes para atender, no solamente a los pacientes (perros, gatos, etc.) sino también a sus dueños.

Aquí se aplica una evaluación continua que pretende seguir el proceso y el progreso que hacen los estudiantes en sus aprendizajes. Una variante interesante que introduce este curso tiene que ver con que los estudiantes no lo repiten ni lo pierden sino que a cada estudiante se le respeta su tiempo - ritmo de aprendizaje y de preparación. Para aprobarlo, el estudiante debe haber cubierto todos los requerimientos acordados al principio del curso. "En suma (dice la docente), no existirá ganancia, pérdida o repetición del curso, sino diferentes tiempos que le llevará a acceder al puntaje final necesario".

\section{h.- Una constatación empírica como disparador de cambios}

Uno de los docentes relata los cambios que experimentó él mismo a partir de una constatación empírica acerca de que sus supuestos previos. Dichos supuestos giraban en torno a lo que sabían o deberían saber sus estudiantes en relación a un tema concreto de Agrometeorología. Esos supuestos, como él mismo comprobó, eran erróneos. Suponía que los estudiantes debían ingresar a la Facultad de Agronomía con conocimientos adquiridos con respecto a 'la medición de la precipitación'. Incluso parecía ser un tema de conocimiento bastante público y nunca se le había ocurrido que fuera necesario diseñar algún dispositivo o alguna estrategia de intervención didáctica en la propia Facultad para que los estudiantes comprendieran esas cuestiones. 
A raíz de estas constataciones el docente implementó una práctica de enseñanza que conlleva también una nueva forma de evaluar. El trabajo se planificó para grupos de seis estudiantes quienes, constantemente consultaban a sus docentes. Cada aspecto del trabajo tuvo una forma particular de ser evaluado y se fueron conociendo los resultados durante la actividad desarrollada. Además de evaluar a cada integrante también se valoró el trabajo grupal a través de instrumentos especialmente elaborados para ello.

\section{II.- La masificación, ¿rige la propuesta evaluativa y la devolución de los resultados?}

Todos los investigados coincidieron en que la masificación es una problemática difícil y compleja. De hecho, uno de los argumentos más comunes que ofrecieron para seguir con las devoluciones más tradicionales es el de la masificación. Hay cursos enteros que se han visto obligados a cambiar sistemas de evaluación que venían aplicando y que podrían tener un valor más didáctico debido a esa masificación.

Muchos docentes explican cómo se vieron obligados a cambiar sus sistemas de evaluación lo que repercutió, aun a su pesar, tanto en las formas de devolución de los resultados como en el desarrollo de sus propios cursos.

De acuerdo con las manifestaciones de la mayoría, la masificación está jugando un papel negativo en los procesos de enseñanza y de aprendizaje. Este factor parece haberse convertido en un fuerte obstáculo para la enseñanza y, consecuentemente, para realizar una adecuada devolución de los resultados de las evaluaciones. Incluso, en la mayoría de los casos estaría determinando el tipo de instrumento y la modalidad de evaluación a emplear. Esta situación no depende directamente de los docentes sino que los excede formando parte de problemas propiamente institucionales. Lo que afirman, en este sentido, es que esta situación está comprometiendo la excelencia en la formación de los profesionales de nuestra Universidad.

\section{III.- La evaluación y la devolución, ¿se conciben como espacios didácticos?}

Es interesante reconocer que, a pesar de que los docentes se preocupan por recuperar la enseñanza a través de las devoluciones de los resultados de las evaluaciones, cuando se les pregunta, específicamente, si consideran ese espacio como parte de la enseñanza, no saben muy bien qué contestar. Uno de los entrevistados, por ejemplo, afirma que si tuviera más tiempo y pudiera elegir entre dar más contenido y dedicarle ese tiempo a la devolución, no dudaría en elegir la primera opción.

Las razones para que estos espacios todavía no sean visualizados como espacios didácticos parecen ser varias: falta de tiempo para abordar todos los contenidos del Programa (currículum excesivamente abigarrado); lo engorroso que resultan las devoluciones, sobre todo si son individuales; la gran cantidad de estudiantes que tienen; etc. Pero, en definitiva la idea es que estos espacios todavía no se visualizarían como verdaderos espacios de enseñanza y de aprendizaje

En este sentido, lo que pudimos reconocer fue que la visión que tienen los docentes de estos espacios no es la misma para todos. Sin embargo, no hubo ninguno que hiciera una negación rotunda en ese sentido. Por el contrario, estamos convencidos de que la cuestión generó dudas y reflexiones profundas.

\section{IV.- Más allá de lo curricular en las devoluciones}

Este hecho se apreció en varios casos. El más paradigmático es el del docente que hace las devoluciones a través de gráficas. Según él, aprovecha esa oportunidad para hacer hincapié en la importancia que tiene el aprender Estadística tanto para los cursos como para la propia profesión. Lo hace en el entendido de que se trata de una materia fuertemente resistida por los estudiantes y cuya utilidad no alcanzan a ver con claridad (el docente no imparte Estadística puesto que la misma se ofrece en cursos posteriores). 
Sin embargo, cuando se le preguntó a este docente si al hacer las devoluciones de esta forma estaba yendo más allá de lo propiamente curricular de su curso, al principio respondió que no, pero luego admitió que, sin quererlo les ofrecía algunas nociones generales acerca de Estadística aunque no era parte del curriculum de su curso.

\section{V.- La cartelera como espacio de controversia}

La construcción de este enunciado fue algo muy interesante y surgió a partir de las diversas entrevistas mantenidas con los docentes. Como ya se mencionó, la devolución de los resultados se hace a través de los espacios públicos: carteleras, páginas Web... Ante diversas alusiones que surgieron durante algunas entrevistas, se vislumbró un tema interesante y se optó por realizar una pequeña profundización mediante algunas preguntas.

A través de las respuestas de los docentes con respecto al tema, se evidenció un interesante campo de controversia nunca antes abordado. Aún los más entusiastas defensores de la forma de devolución tradicional manifestaban algunas dudas y preocupaciones, por sutiles que fueran, acerca de su legitimidad. Algunos, los menos, se manifestaron en forma absolutamente contundente afirmando que esta forma de devolución era la más conveniente y, por supuesto, ofreciendo argumentos tales como el de que ofrecían una 'mayor transparencia'.

Otros afirmaban que dejaba a los estudiantes expuestos, muchas veces, atentando contra su autoestima y desalentándolos en sus aprendizajes.

La cuestión de las devoluciones a través de espacios públicos parece centrarse más en los aspectos que involucran lo moral y lo ético, vinculado al hecho de 'hacer público lo privado'. Las controversias surgieron a través de preguntas como las siguientes: ¿Cómo afecta esto a los alumnos, a su autoestima, a su aprendizaje, a su avance? La Institución y los docentes, ¿tienen derecho a hacer público algo que es tan personal y que tantas consecuencias (negativas o positivas) puede tener en otro ser humano? ¿Se ha planteado alguna vez en la Institución o, por lo menos, a nivel de los docentes o de estudiantes?

La cuestión nos remite al compromiso social y humano que asumamos como docentes y como personas. En ese sentido cabría preguntarse si queremos seguir siendo cómplices de la formación de sociedades cada vez más competitivas o apostamos a la construcción de sociedades más humanizadas. En las cuestiones de la educación podría aplicarse lo Marshall Mcluhan afirmó en sus trabajos: "El medio es el mensaje" (1967). En este sentido, también la forma de enseñar y, consecuentemente, la forma de evaluar y de devolver los resultados de las evaluaciones, son mensajes, tal vez mucho más subliminales que otros pero, sin duda, muy potentes.

\section{Conclusiones}

La temática abordada en este trabajo giró en torno al sentido didáctico y curricular de las evaluaciones en la Universidad de la República. Ello se hizo en función de las dinámicas informativas generadas por los docentes a partir de los resultados de las mismas. En este sentido, la investigación se centró en la identificación, descripción e interpretación de las propuestas de devolución de resultados de las evaluaciones de los aprendizajes que utilizan algunos docentes del nivel universitario con el fin de mejorar sus prácticas de enseñanza. Todo este trabajo nos permitió construir algunos enunciados teóricos que tal vez puedan iluminar algunos aspectos de la enseñanza y de la evaluación. La construcción de estos enunciados nos llevó a ciertas conclusiones, entre las que se destacan las siguientes:

\section{1) La enseñanza se vuelve una preocupación relacionada con la evaluación}

Lo primero que se evidenció fue una preocupación de los docentes investigados por la búsqueda de una enseñanza responsable. Los datos obtenidos dan cuenta de esta búsqueda. La preocupación de los docentes es la de recuperar la enseñanza, en este caso, a través de la evaluación: de una 
evaluación más justa. Los docentes buscan afanosamente criterios más adecuados para realizar la corrección y la devolución de las evaluaciones y parece haber un compromiso real por cumplirlos. Al mismo tiempo se genera una tensión entre evaluar todos los temas de sus abigarrados curricula y el logro de una evaluación más sensata que puedan utilizar para tomar posteriores decisiones didácticas.

\section{2) La preocupación por la enseñanza: un secreto que cuesta hacerse público}

Todos los docentes investigados, sin excepción, se preocupan por llevar adelante una 'enseñanza responsable'. La prueba de esta preocupación por la enseñanza se manifiesta continuamente, aunque más a nivel implícito que explícito. Cuando se alude al tema se utilizan distintos eufemismos intentando no explicitar demasiado esta cuestión. Lo curioso es comprobar cuánto les cuesta a nuestros docentes admitir abiertamente esta preocupación. Tal vez podría decirse que aquí el peso de la tradición académica (lógica de la disciplina, énfasis casi exclusivo en la investigación, etc.) puede considerarse como un obstáculo implícito pero potente para lograr llegar a una enseñanza más profesional. Este hecho podría estar impidiendo a los colectivos universitarios discutir abiertamente acerca del tema. Ésta es una de las grandes cuestiones que quedaría abierta a futuras profundizaciones: poder investigar realmente cuál es el peso de esas tradiciones y las motivaciones que subyacen en esa actitud. El poder hacer público este aparentemente pequeño pero fundamental 'gran secreto' tal vez contribuiría a mejorar la enseñanza en la Universidad de la República.

\section{3) Una crítica esperanzadora}

Los docentes critican su labor, sobre todo en relación a las formas en las que evalúan y en las formas en que hacen las devoluciones correspondientes. Aluden, entre otras causas, a la falta de formación en aspectos importantes del campo pedagógico - didáctico. Sin embargo, muestran una actitud esperanzadora cuando manifiestan que muchos de los déficits que tienen con respecto a las labores como enseñantes se podrían solucionar con una ayuda pedagógico - didáctica adecuada. En general, son conscientes de sus errores y hasta de sus ignorancias en materia pedagógica.

\section{4) Hacer público lo privado: una cuestión controvertida}

Una conclusión muy interesante a la que se pudo llegar es que la divulgación de los resultados de las evaluaciones a través de espacios públicos como son las carteleras, páginas Web y otros, genera una interesante controversia que hace de un tema, aparentemente 'inocuo' un gran tema para seguir reflexionando en los ámbitos universitarios. El mismo presenta ciertas aristas que exceden la propia evaluación y hasta el propósito mismo de este trabajo.

\section{Síntesis}

La preocupación inicial al proponer esta investigación, fue la de explorar el sentido que le daban a las evaluaciones de los aprendizajes los docentes. Se buscaba saber, fundamentalmente, si el mismo era un sentido didáctico o un sentido de simple acreditación.

Esta exploración se hizo en función de la identificación, descripción e interpretación de las propuestas de devolución de resultados de las evaluaciones de los aprendizajes que utilizan algunos docentes del nivel universitario. A través de ellas se pretendió comprobar si los docentes buscaban mejorar sus prácticas de enseñanza. El resultado demuestra que esa es una de sus preocupaciones. Ello parece estar indicando que el sentido que le atribuyen a las evaluaciones no sería simplemente un sentido de acreditación sino también un sentido fuertemente didáctico aunque, muchas veces, los propios docentes no sean plenamente conscientes de ello. 
Para terminar podría decir que una sensación quedó 'latiendo' en muchos de los docentes entrevistados: una conciencia real de la gran responsabilidad que nuestra labor entraña y de la que, a veces, nos olvidamos. Esta responsabilidad como enseñantes se da en todo momento y reflexionar en torno a ella tal vez nos permita optimizar nuestra tarea.

\section{Bibliografía utilizada en la investigación}

Allen, D. 2000. La evaluación del aprendizaje de los estudiantes. Buenos Aires: Paidós. Allidiere , N. 2004. El vínculo profesor - alumno. Buenos Aires: Biblos.

Álvarez Mendez, M. 2000. Evaluar para conocer, examinar para excluir. Madrid: Morata. Álvarez Mendez, M., LÓPEZ, J. 1999. La evaluación del profesorado y de los equipos docentes. Madrid: Síntesis.

Ander Egg, E. 1993. Técnicas de investigación social. Buenos Aires: Magisterio del Río de la Plata.

Astolfi, J. 1997. Aprender en la escuela. Santiago de Chile: Dolmen.

Becher, T. 2001. Tribus y territorios académicos: la indagación intelectual y las culturas de las disciplinas. Barcelona: Gedisa.

Bain, K. 2007. Lo que hacen los mejores profesores universitarios. Valencia: Publicaciones de la Universidad de Valencia.

Beane, J. A. 2005. La integración del currículum: el diseño del núcleo de la educación democrática. Madrid: Morata.

Bernstein, B. 1990. Poder, educación y conciencia: sociología de la transmisión cultural. Barcelona: El Roure.

Blythe, T. 2002. La enseñanza para la comprensión: guía para el docente. Buenos Aires: Paidós.

Bourdieu, P. 1987. Cosas Dichas. Barcelona: Gedisa.

Brown, S.; Glasner, A. 2003. Evaluar en la Universidad: problemas y nuevos enfoques. Madrid: Narcea.

Bruner, J. 1997. La educación, puerta de la cultura. Madrid: Aprendizaje Visor.

Bruner, J. 1988. Realidad mental y mundos posibles: los actos de imaginación que dan sentido a la experiencia. Madrid: Gedisa.

Cabrera, F. A. 2003. Evaluación de la formación. Madrid: Síntesis.

Camilloni, A. et al. 1997. Corrientes didácticas contemporáneas. Buenos Aires: Paidós.

Capra, F. 1998. La trama de la vida: una nueva perspectiva de los sistemas vivos. Barcelona: Anagrama.

Carlino, F. R. 1999. La evaluación educacional: historias, problemas y propuestas. Buenos Aires: Aique.

Carr. W.; Kemmis, S. 1988. Teoría crítica de la enseñanza. Barcelona: Martínez Roca.

Cea D’ancona, M. A. 1996. Metodología cuantitativa: estrategias y técnicas de investigación social. Madrid: Síntesis. 
Condemarín, M.; Medina, A. 2000. Evaluación auténtica de los aprendizajes: un medio para mejorar las competencias en lenguaje y comunicación. Santiago de Chile: Andrés Bello.

Cook, T.; Reichardt, Ch. 1995. Métodos cualitativos y cuantitativos en investigación evaluativa. Madrid: Morata.

De La Torre, S. 2004. Aprender de los errores: el tratamiento didáctico de los errores como estrategia de innovación. Buenos Aires: Magisterio del Río de la Plata.

De La Torre, S. 2000. Estrategias didácticas innovadoras: recursos para la formación y el cambio. Barcelona: Octaedro.

Demarchi, M.; Dumar, D. 1991. Mitos y realidades en la formación docente. Montevideo: Aula.

De Sousa Santos, B. 2004. La universidad en el siglo XXI: para una reforma democrática y emancipadora de la universidad. Buenos Aires: Miño y Dávila.

Díaz Barriga, Á. 1994. Docente y programa: lo institucional y lo didáctico. Buenos Aires: Aique.

Díaz Barriga, Á. 1991. Didáctica: aportes para una polémica. Buenos Aires: Aique.

Díaz Barriga, Á. 1990. Didáctica y curriculum. Ciudad de México: Nuevomar.

Eco, H. 1993. Cómo se hace una tesis: técnicas y procedimientos de investigación, estudio, escritura. Barcelona: Gedisa.

Eisner, E. 1998. El ojo ilustrado: indagación cualitativa y mejora de la práctica educativa. Barcelona: Paidós.

Eisner, E. 1998. Cognición y currículum. Una visión nueva. Buenos Aires: Amorrortu.

Foucault, M. 1975. Vigilar y castigar. $21^{\mathrm{a}}$ ed. Barcelona: Siglo XXI.

Foucault, M. 1966. Las palabras y las cosas: una arqueología de las ciencias humanas. 20ª ed. México: Siglo XXI.

García - Valcárcel, A. 2001. Didáctica universitaria. Madrid: La Muralla. GVIRTZ, S.

Palamidessi, M. 1998. EI ABC de la tarea docente: currículum y enseñanza. Buenos Aires: Aique.

Hargreaves, A. et al. 2003. Replantear el cambio educativo: un enfoque renovador. Buenos Aires: Amorrortu.

Hargreaves, A. et al. 1998. Una educación para el cambio: reinventar la educación de los adolescentes. Barcelona: Octaedro.

Hernández, F.; SANCHO, J. M. 1996. Para enseñar no basta con saber la asignatura. Buenos Aires: Paidós.

Jackson, Ph. et al. 2003. La vida moral en la escuela. Buenos Aires: Amorrortu.

Jackson, Ph. 2002. Práctica de la enseñanza. Buenos Aires: Amorrortu.

Jackson, Ph. 1999. Enseñanzas implícitas. Buenos Aires: Amorrortu.

Kemmis, S. 1998. El currículum: más allá de la teoría de la reproducción. Madrid: Morata.

Kincheloe, J. 2001. Hacia una revisión crítica del pensamiento. Barcelona: Octaedro.

Liston, D. P. Zeichner, K. M. 1997. Formación del profesorado y condiciones sociales de la escolarización. La Coruña: Morata. 
Litwin, E. 1997. Las configuraciones didácticas: una nueva agenda para la enseñanza superior. Buenos Aires: Paidós.

López, B. S.; Hinojosa, E. M. 2001. Evaluación del aprendizaje: alternativas y nuevos desarrollos. México: Trillas.

Lucarelli, E. et al. 2000. El asesor pedagógico en la universidad: de la teoría pedagógica a la práctica en la formación. Buenos Aires: Paidós.

Martín Molero, F. 1999. La didáctica ante el tercer milenio. Madrid: Síntesis.

McEvan, H.; Egan, K. 1998. La narrativa en la enseñanza, el aprendizaje y la investigación. Buenos Aires: Amorrortu.

McLaren, P. 1995. La escuela como un performance ritual: hacia una economía política de los símbolos. México: Siglo XXI.

McLuhan, M. 1967. El medio es el masaje. Barcelona: Paidós.

Meirieu, Ph. 1992. Aprender, sí. Pero ¿cómo? Barcelona: Octaedro.

Monereo, C.; Pozo, J. I. 2003. La universidad ante la nueva cultura educativa: enseñar y aprender para la autonomía. Madrid: Síntesis.

Morin, E.; 1998. Introducción al pensamiento complejo. Barcelona: Gedisa.

Onrubia, J. et al. 2004. Criterios psicopedagógicos y recursos para atender la diversidad en secundaria. Barcelona: Graó.

Popkewitz, Th. et al. 1994. Modelos de poder y regulación social en Pedagogía: crítica comparada de las reformas contemporáneas de la formación del profesorado. Barcelona: Pomares.

Prigogine, I. 1997. El fin de las certidumbres. Santiago de Chile: Andrés Bello.

Puiggrós, A. 1994. Universidad y evaluación. Estado del debate. Buenos Aires: Aique.

Rodríguez, H. M.; García, E. 1992. Evaluación en el aula. México: Trillas.

Rosales, C. 1988. Criterios para una evaluación formativa. Madrid: Narcea.

Sabino, C. 1986. El proceso de investigación. Caracas: Humanitas.

Sagastizabal, J.; et al. 2006. Aprender y enseñar en contextos complejos. Buenos Aires: Noveduc.

Sánchez Cerezo, S. 1996. Diccionario de las Ciencias de la Educación. Madrid: Santillana.

Segovia Pérez, J. 1997. Investigación educativa y formación del profesorado. Madrid: Escuela Española.

Sierra Bravo, R. 1984. Ciencias Sociales. Epistemología, Lógica y Metodología. Madrid: Paraninfo.

Sierra Bravo, R. 1988. Técnicas de investigación social. Teoría y ejercicios. Madrid: Paraninfo.

Stemberg, R.; Grigorenko, E. 2003. Evaluación dinámica. Naturaleza y mediación del potencial de aprendizaje. Barcelona: Paidós.

Stenhouse, L. 1987. La investigación como base de la enseñanza. Madrid: Morata.

Stufflebeam, D.; Shinkfield, A. J. 1993. Evaluación sistemática. Guía teórica y práctica. Barcelona: Paidós. 
Taylor, S. J.; Bogdan, R. 1996. Introducción a los métodos cualitativos de investigación. Buenos Aires: Paidós.

Torres, J. 1992. El currículum oculto. Madrid: Morata.

Valles, M. 1997. Técnicas cualitativas de investigación social: reflexiones metodológicas y práctica profesional. Madrid: Síntesis.

Wainerman, C.; Sautu, R. 2000. La trastienda de la investigación. Buenos Aires: Lumiére.

Wittrock, M. 1989. La investigación de la enseñanza: enfoques, teorías y métodos. Vol.

1. Barcelona: Paidós.

Wittrock, M. 1989. La investigación de la enseñanza: métodos cualitativos y de observación. Vol. 2. Barcelona: Paidós.

Woods, P. 1998. Investigar el arte de la enseñanza. El uso de la etnografía en la educación. Barcelona: Paidós.

\section{Notas y citas}

${ }^{1}$ Esta es una interesante expresión utilizada por Hargreaves (1998) y de la que se puede inferir sentidos que se le da a la evaluación.

${ }^{2}$ cf. Taylor y Bogdan, 1987.

${ }^{3}$ Sarason, 2002: 19. La enseñanza como arte de representación.

*El Artículo se enmarca en la tesis de maestría de la autora, dirigida por la Dra. Edith Litwin. Año 2008.

**Master en Educación con mención en investigación en enseñanzas y aprendizajes. Diplomado Superior en Ciencias Sociales con mención en Constructivismo y Educación. Licenciada en Lingüística. Maestra. 